\title{
A guide to do randomized controlled trials in the field of otolaryngology
}

\author{
Sameh M. Zamzam (D), Mosaad Abdel-Aziz, Ahmed Atef, Usama Abdel-Naseer, Mostafa Hamoda, Mohamed Salah, \\ Hazem Dewidar, Louay Elsharkawy and Mena E. Abdelmalek
}

\begin{abstract}
Background: Randomized controlled trials (RCTs) are prospective comparative studies in which study groups are allocated randomly to intervention or serve as controls. RCT is the mainstay to achieve evidence in the literature in clinical research. A RCT is the main research design to study the effect of an intervention and the only way to confirm the value of a new treatment.
\end{abstract}

Main body: RCT also gives the way to generate meta-analyses and systematic reviews giving a stronger evidence for clinical practice. Evidence-based medicine (EBM) is crucial for safe, effective, and standardized patient care. Although there is an agreement on the importance of performing RCT, it can be challenging to do it efficiently including different aspects like study design, funding, randomization, blinding, follow-up, data analysis, statistics, generalization of results, and reporting of quality of the studies.

Conclusion: In this article, we gave a comprehensive review for RCT in otolaryngology discussing their importance, advantages, and drawbacks, types, steps, challenges, reporting their quality and their prevalence in the literature.

Keywords: Study design, Randomized clinical trials, Otolaryngology, Research

\section{Background}

RCT is a study in which subjects are randomly assigned into groups including a control group, to receive or not receive intervention under study. The study results are determined by comparing outcomes of interest between different groups and their statistical analysis to determine whether the difference is clinically significant or not. The terms "randomized control trial" and "randomized trial" are usually used interchangeably. However, "randomized control trial" refers to the comparison between intervention and control groups while "randomized trial" refers to the comparison between multiple intervention groups [1].

Sir Bradford Hill (1897-1991) was the first to publish RCT in medicine. He is a British epidemiologist and statistician and is considered to be the father of modern RCT. There is a progressive increase in the number of

\footnotetext{
* Correspondence: samehzamzam@hotmail.com

ENT Department, Kasr Alainy Hospital, Garden city, Cairo, Egypt
}

published articles in otolaryngology. This opened the way for more evidence-based treatment recommendations and well-settled guidelines. However, this provided new challenges for otolaryngologists including continuous review for updates in the published research, ability to assess its quality, provide continuously updated treatment guidelines, and individualizing patient care according to the most recent available evidence in the literature $[2,3]$.

\section{Main text \\ Importance of RCTs}

Evidence from RCTs and subsequently systematic reviews lies at the top of the pyramid of evidence and is considered the most important source for evidencebased clinical decisions. On contrary, in observational studies, there are often differences in characteristics between study groups, this will result in bias because the outcome may differ due to such differences not due to the intervention itself. The only way to overcome this

\section{Springer Open}

(c) The Author(s). 2021 Open Access This article is licensed under a Creative Commons Attribution 4.0 International License, which permits use, sharing, adaptation, distribution and reproduction in any medium or format, as long as you give appropriate credit to the original author(s) and the source, provide a link to the Creative Commons licence, and indicate if changes were made. The images or other third party material in this article are included in the article's Creative Commons licence, unless indicated otherwise in a credit line to the material. If material is not included in the article's Creative Commons licence and your intended use is not permitted by statutory regulation or exceeds the permitted use, you will need to obtain permission directly from the copyright holder. To view a copy of this licence, visit http://creativecommons.org/licenses/by/4.0/. 
bias is to randomly allocate individuals to the desired intervention or control [4].

This article gives an overview of the different types and steps you can follow to do randomized controlled trials. It also focuses on their advantages and drawbacks and how to avoid these mistakes during the study. Furthermore, it gives a quick review about reporting the quality of RCTs and the prevalence of RCTs in otolaryngology in recent decades.

\section{Types of randomized clinical trials}

- Randomized controlled clinical study: Evaluates therapeutic agents like drugs, e.g., evaluation of levocetirizine in treating allergic rhinitis.

- Preventive study: Study primary prevention methods, e.g., coronavirus disease-19 (COVID-19) vaccination.

- Risk factor study: Intervention to stop a risk factor that shares in the development of a disease, e.g., treatment of single laryngeal papilloma to protect against laryngeal cancer.

- Cessation study: Evaluate the cessation of a habit causing a disease, e.g., alcohol and cancers of the larynx and pharynx.

- Etiologic agents' study: To confirm or reject the possible role of the etiologic factor for a disease.

- Evaluation of health system: To evaluate the effectiveness of the health system in the prevention and treatment of certain diseases to reduce the burden on national costs, e.g., the effectiveness of specific hospital infection control measures to reduce the incidence of intensive care unit (ICU) morbidity [5].

\section{Types of controls in randomized controlled clinical trials}

- Placebo control: Study participants in the control group receive treatment that contains no active drug.

- No treatment control: Study participants in the control group receive no treatment, so they are not blind to treatment allocation.

- Active (positive) control: Study participants in the control group receive an active treatment, e.g., managing otitis media with effusion with ventilation tube insertion versus medical treatment.

- Dose response control: The study investigates the effect of different doses of the same treatment so different groups are given different doses, e.g., investigating optimal steroids dose in Bell's palsy.

- External control: The control group used is outside the current study, being treated at an earlier time (historical control) or in another setting.
- Multiple control groups: Using more than one type of the previously mentioned controls [6].

\section{Advantages and drawbacks of RCTs Advantages}

- Effective in eliminating selection bias and controls confounding bias without adjustment due to similar characteristics of study groups.

- Control of exposure to intervention; including time, amount, frequency, and duration.

- High statistical power can be achieved.

- Allows comparison of multiple outcomes.

- Optimal for publication.

\section{Drawbacks}

- Complex, expensive, time-consuming, sometimes ethically questionable.

- Artificial environment, if strict eligibility criteria are applied, the generalizability of results will be questionable.

- Select subjects who will comply to the treatment regimen and strict follow-up, this may compromise the generalizability of results.

- Cannot be used for rare outcomes or outcomes needing very long follow-up [7].

\section{Steps of conducting a RCT design Formulating study question}

A RCT is generally used to test an intervention, which needs to be verified, exploring its safety and effectiveness. The proposed intervention should be safe and ethically approved. Observational studies can provide an idea about the effect of a specific intervention, but they are generally liable to bias. RCTs are used to study treatment methods and diagnostic tools but they are not appropriate or practical for studying etiology, natural history of disease, rare outcomes, or outcomes that take a very long time to occur [8].

Study hypothesis can be classified into:

- Superiority study: An intervention is supposed to be better than another one and the difference is statistically significant.

- Non-inferiority study: An intervention is supposed to be not worse than a reference intervention in a statistically significant way.

- Equivalence study: Two interventions are supposed to be equal in statistical significance [9].

RCTs can be classified according to outcome into: 
- Explanatory study: Explores if the study intervention works and its mechanism.

- Pragmatic study: In addition to studying if the interventions work, it assesses all the results of the intervention and its use under real situations of the clinical practice.

- Efficacy study: Tests the effect of intervention on the people receiving it.

- Effectiveness study: Tests the effect of intervention in the people offered the intervention [5].

\section{Selection of participants}

Inclusion and exclusion criteria Inclusion criteria aim to identify the patients in whom the intervention is appropriate and likely to lead to the tested outcome. Included subjects should be representative of the population of interest and inclusion criteria should not be too restricted so that the generalizability of the results is affected. Exclusion criteria should include patients in which risk of treatment toxicity is unacceptable, likely ineffective, having comorbidities interfering with the intervention, or unlikely to comply with the intervention and follow-up. In general, there should be a balance between choosing the appropriate participants without being too restricted at the expense of the generalizability of results. Both inclusion and exclusion criteria are very significant in minimizing sampling or referral bias [10].

\section{Sample size}

According to the number of participants, RCTs are classified into:

- Fixed trials: Fixed number of subjects is calculated using statistical methods before the start of the intervention.

- Mega trials: Include thousands of patients from multiple centers. This increases statistical power and generalizes the results.

- Sequential trials: The number of subjects is not specified. The researchers continue recruiting participants until a clear outcome.

- Individual patient trials include one patient. The results cannot be generalized.

Adequate sample size and power are important to be able to generalize the study conclusions to the targeted population with confidence. This number is often determined by previous trials, observations, experiments, or consensus opinion. Specific statistical methods are used to obtain a valid number. In general, when the group characteristics are less variable, a smaller group size will be needed to prove that the difference is mostly not due to chance and is most probably due to the intervention.
A very small sample size increases the chance that the effect of the intervention won't be significant, even if it has a real effect (type 2 error). A type I error refers to the rejection of the null hypothesis while it is true, a type II error refers to the failure of rejection of the null hypothesis while it is false [11].

\section{Trial phases}

Clinical trials assessing pharmaceutical agents should run a course of studies to determine if they are safe and effective before being permitted for clinical use. There are four steps of clinical trials to be completed.

- Phase I: Studying drug pharmacology in human, like studying the absorption, excretion, and toxicity. They are done in a small number of volunteers nearly 20-80.

- phase II: Exploring therapeutic efficacy, estimating dose, and confirming the safety in a slightly larger number of participants nearly 100-300.

- Phase III: Confirming the therapeutic effect of the drug, using adequate sample size for proper confirmation before clinical use of the drug.

- phase IV: Done after drug approval by health authorities like FDA or European medicines agency as post-marketing studies to give more data about uses, side effects, and optimizing dose [12].

\section{Baseline measurements}

- Describe subjects' demographics: age, sex, etc. They may especially important to emphasize that the randomization process worked.

- Participants' contact information that helps in avoiding loss of follow-up during the study including phone number, home address, or contact information of a friend or family member to contact if the participant is not reachable.

- Identify prognostic factors of the outcome that can be identified, e.g., if a side effect of the drug is thought to be more common in females, so collecting data on gender is crucial [6].

\section{Randomization}

Important to eliminate confounding and selection bias and balance prognostic variables in all groups.

\section{Criteria of randomization}

- Unpredictability: Giving the same chance for every study subject to be allocated to any of the interventions or control groups.

- Equality: Ensuring that study groups have the same number and baseline characteristics. 
- Simplicity: Choosing an easy way to be done by the researcher [13].

\section{Methods of randomization}

- Simple randomization: Randomization is like flipping a coin. The most common methods are random number table and randomization computer programs to generate random numbers. It is simple and easy but a number of subjects in each study group may be different especially in small studies [13].

- Stratified randomization: Control and balance the influence of covariates. Subjects are firstly divided into blocks of covariates then simple randomization is done within each block to allocate subjects to the study groups. It may be particularly useful with a small number of subjects. No need for stratified randomization in large clinical trials because participants' characteristics are adequately balanced in study groups [14].

- Block randomization: Especially useful with small sample size to provide an equal size of study groups all time. The block size should be a multiple of the number of study groups (e.g., if there are 2 study groups, block size can be 4,6 , or 8 ). The main disadvantage is that the participants randomized in the last of the block can predict their study group, so they will not be blinded to the selection and its application is very difficult [15].

- Unequal randomization: Like allocating fewer number of participants to the more expensive intervention and more number to the cheaper one. The results are usually of low statistical power [15].

\section{Blinding}

It is important to eliminate measurement bias.

\section{Types of blinding}

- Open: Study participants, investigators, and statistician know each participant is allocated to which intervention or control (not blinded).

- Single-blind: Study participants or investigators are blinded to the intervention, but not both of them.

- Double-blind: Study participants and investigators are blinded to the intervention.

- Triple-blind: Participants, investigators, and statisticians are blinded [16].

\section{Intervention}

According to participants' exposure to the intervention, RCTs can be classified into:

- Parallel: The most commonly used type, treatment, and control interventions are given to different individuals e.g. studying endoscopic myringoplasty and comparing it to microscopic myringoplasty as control. They generally require larger sample size to produce statistically significant results.

- Crossover: Every participant receives both treatments, but their order is randomized. Therefore, each participant is considered his own control, and subsequently less sample size is needed.

- Factorial: It allows investigating the joint effect of two or more factors together, e.g., in Reinke's edema, one can study the effect of medical treatment alone versus surgery versus both together versus control. It also facilitates the study of interactions.

- Cluster: Randomization is done to a whole group of subjects, e.g., allocating the intervention to a whole hospital or department and control to another hospital or department. It can be used to assess interventions that cannot be applied to separate subjects like comparing the effect of specific infection control measures on the incidence of certain hospital infections [17].

\section{Follow-up of subjects}

Compliance to protocol and avoidance of follow-up loss are important aspects for RCT. Loss of follow-up, noncompliance, and contamination (Patients cross from one study group to the other) are important potential problems in RCTs. They will lead to reduced statistical power due to decreased subjects. If they occurred in a nonrandom manner, i.e., in a group more than the other, which is often the case, they will lead to bias [18].

\section{Measurement of outcome}

- Primary and secondary outcomes are assessed.

- Positive results/negative results could be obtained.

- Adverse events are reported

- Intention-to-treat analysis: a method to analyze results in RCT, for each group separately regardless of the received treatment in each group's participants [3].

\section{Statistical analysis}

Statistical analysis of RCTs is usually straightforward as all factors other than the intervention itself are balanced, allowing accurate comparison of the study outcomes between different groups. The $t$ test is usually used for continuous outcomes, while the chi-square test is used for categorical outcomes. Non-parametric tests may be used if the sample size is small or when the outcomes are not normally distributed. In survival studies, the Kaplan-Meier curve or advanced COX regression model is used to be able to estimate the outcome over time. If the population parameters such as mean and standard 
Table 1 Prevalence of RCTs in the field of otolaryngology in the last 2 decades

\begin{tabular}{|c|c|c|c|c|}
\hline \multirow[t]{3}{*}{ Journal } & \multicolumn{2}{|l|}{ Yao et al. 2007 [22] } & \multicolumn{2}{|l|}{ Banglawala et al. 2015 [23] } \\
\hline & \multicolumn{2}{|l|}{ Years 2000-2005 } & \multicolumn{2}{|l|}{ Years 2011-2013 } \\
\hline & $\begin{array}{l}\text { Number of RCTs/total number } \\
\text { of articles }\end{array}$ & $\begin{array}{l}\text { Number of } \\
\text { RCTs }\end{array}$ & $\begin{array}{l}\text { Number of RCTs/total number } \\
\text { of articles }\end{array}$ & $\begin{array}{l}\text { Number of } \\
\text { RCTs }\end{array}$ \\
\hline $\begin{array}{l}\text { The Annals of Otology, Rhinology and } \\
\text { Laryngology }\end{array}$ & $\begin{array}{l}202 / 5467 \\
(3.7 \%)\end{array}$ & $15(7 \%)$ & $\begin{array}{l}189 / 5729 \\
(3.3 \%)\end{array}$ & $24(13 \%)$ \\
\hline $\begin{array}{l}\text { Archives of Otolaryngology - Head and Neck } \\
\text { Surgery (JAMA) }\end{array}$ & & $50(25 \%)$ & & $26(14 \%)$ \\
\hline The Laryngoscope & & $86(43 \%)$ & & $74(39 \%)$ \\
\hline Otolaryngology_Head and Neck Surgery & & $51(25 \%)$ & & 65 (34\%) \\
\hline
\end{tabular}

deviation (SD) of the present study are claimed to be equal to previous data analysis, this is known as the null hypothesis $\left(\mathrm{H}_{0}\right)$; on the other hand, the alternative hypothesis $\left(\mathrm{H}_{1}\right)$ is the actual data analysis of the present study [19].

\section{Non-randomized controlled trials}

Unlike RCTs, study participants are not assigned to interventions or control in a random way but according to the decision of the investigator, so characteristics of participants are not similar across study groups. To rightly assess the effect of the intervention, differences in participants' characteristics between different groups should be controlled in data analysis. If not done, it usually overestimates the advantages of one intervention over another.

It may be used instead of RCT in the following situations:

- When it may decrease the effectiveness of the intervention.

- When it would be unethical or illegal.

- When it is impractical (e.g., costly) [20].

\section{Reporting quality of RCTs}

RCTs are considered the best way for "rational therapeutics" in medical practice. There may be a big difference in quality between different RCTs. To standardize the method of reporting quality of RCTs and include all important aspects in the evaluation process, a team of scientists created the CONSORT (Consolidated, Standards Of Reporting Trials) statement. It is a checklist and flow diagram that include all important aspects for the quality of the RCT including for example the study design, randomization, blinding, and results. It is now the most agreed method for reporting the quality of RCTs [21].

\section{Prevalence of RCTs in the field of otolaryngology in the last 2 decades}

Yao et al. in 2007 reviewed all RCTs of treatment efficacy in 6 years from 2000 to 2005 in 4 major otolaryngology journals in relation to the volume of published research. Banglawala et al. in 2015 reviewed all RCTs of treatment efficacy in three years from 2011 to 2013 in the same journals, compared with the previous study, there is an approximate doubling in volume of yearly published articles, but there is a decrease in the percentage of published RCTs. Banglawala et al. concluded that RCTs represent a small percentage out of the whole published research in otolaryngology; however, the quality and reporting of RCTs are improving (Table 1) [22, 23].

\section{Conclusion}

In this article, we gave a comprehensive review for RCT in otolaryngology discussing their importance, advantages, drawbacks, types, steps, challenges, reporting their quality, and their prevalence in the literature.

This current study gives a step-by-step guide to do a $\mathrm{RCT}$ in the field of otolaryngology when compared to previous similar studies.

RCT has chief characters: unpredictable distribution and equality of participants in both groups, high statistical power which makes it optimal for publication. The main cornerstones of RCT are to determine the control group, sample size, method of randomization, type of blinding, and exposure.

RCT should be limited to settings and subjects with characteristics similar to the study settings and subjects.

Future studies are needed to assess the prevalence of RCT in different topics in the field of otolaryngology in different local, regional, and international journals.

\section{Abbreviations}

RCT: Randomized clinical trial/randomized controlled trial; EBM: Evidencebased medicine

\section{Acknowledgements}

Not applicable

Authors' contributions

SM contributed to putting the methods, data collection, shared in writing the paper and submitting the paper. MA and AA contributed to the application of the idea, steps of the methods, and supervising the study work. UA, MH, MS, HD, and LE supervised the work. ME contributed to the 
data collection and writing the paper. All authors have read and approved the manuscript.

\section{Funding}

None

\section{Availability of data and materials}

Data are available from the corresponding author on reasonable request

\section{Declarations}

\section{Ethics approval and consent to participate}

This study has been approved by the ethical committee of the ENT department, Cairo University.

Reference number: not applicable in our institute

Written informed consents were obtained

\section{Consent for publication}

Written informed consents were obtained

\section{Competing interests}

Prof Ahmed Atef is a co-author of this study and the Editor-in-Chief of the journal. He declares a competing interest for this submission. He has not handled this manuscript. The rest of the authors have no conflict of interest to declare.

Received: 11 June 2021 Accepted: 4 July 2021

Published online: 21 July 2021

\section{References}

1. Deaton A, Cartwright N (2018) Understanding and misunderstanding randomized controlled trials. Soc Sci Med 210:2-21. https://doi.org/10.1016/ j.socscimed.2017.12.005

2. Murad MH, Asi N, Alsawas M, Alahdab F (2016) New evidence pyramid. BMJ Evid Based Med 21(4):125-127. https://doi.org/10.1136/ebmed-2016-110401

3. Jadad AR, Enkin MW (2007) Randomized controlled trials: questions, answers and musings, 2nd edn. BMJ Books, London. https://doi.org/10.1002/97804 70691922

4. Howards PP (2018) An overview of confounding. Part 1: the concept and how to address it. Acta Obstet Gynecol Scand 97(4):394-399. https://doi. org/10.1111/aogs.13295

5. Stolberg HO, Norman G, Trop I (2004) Randomized controlled trials. Am J Roentgenol 183(6):1539-1544. https://doi.org/10.2214/ajr.183.6.01831539

6. Rajagopalan R, Deodurg PM, Badgal S (2013) Overview of randomized controlled trials. Asian J Pharm Clin Res 6(3):32-33

7. Li G, Sajobi TT, Menon BK, Korngut L, Lowerison M, James M, Wilton SB, Williamson T, Gill S, Drogos LL, Smith EE (2016) Registry-based randomized controlled trials-what are the advantages, challenges, and areas for future research? J Clin Epidemiol 80:16-24. https://doi.org/10.1016/j.jclinepi.2016. 08.003

8. Wilson MP, Guluma KZ, Hayden SR (2015) How do I formulate a research question? In: In doing research in emergency and acute care. https://doi. org/10.1002/9781118643440.ch3

9. Hwang IK, Morikawa T (1999) Design issues in noninferiority/equivalence trials. Ther Innov Regul Sci 33(4):1205-1218

10. Patino CM, Ferreira JC (2018) Inclusion and exclusion criteria in research studies: definitions and why they matter. J Bras Pneumol 44(2):84-84. https://doi.org/10.1590/s1806-37562018000000088

11. Moher D, Dulberg CS, Wells GA (1994) Statistical power, sample size, and their reporting in randomized controlled trials. JAMA 272(2):122-124. https://doi.org/10.1001/jama.1994.03520020048013

12. Stanley K (2007) Design of randomized controlled trials. Circ Res 115(9): 1164-1169. https://doi.org/10.1161/CIRCULATIONAHA.105.594945

13. Broglio K (2018) Randomization in clinical trials: permuted blocks and stratification. JAMA 319(21):2223-2224. https://doi.org/10.1001/jama.2018.63 60

14. Weir CJ, Lees KR (2003) Comparison of stratification and adaptive methods for treatment allocation in an acute stroke clinical trial. Stat Med 22(5):705726. https://doi.org/10.1002/sim.1366
15. Lachin JM, Matts JP, Wei $\amalg J$ (1988) Randomization in clinical trials: conclusions and recommendations. Control Clin Trials 9(4):365-374. https:// doi.org/10.1016/0197-2456(88)90049-9

16. Wood L, Egger M, Gluud LL, Schulz KF, Jüni P, Altman DG, Gluud C, Martin RM, Wood AJ, Sterne JA (2008) Empirical evidence of bias in treatment effect estimates in controlled trials with different interventions and outcomes: meta-epidemiological study. BMJ 336(7644):601-605. https://doi. org/10.1136/bmj.39465.451748.AD

17. Donner A, Klar N (2000) Design and analysis of cluster randomization trials in health research. Arnold, London, p 178

18. Mathieu E, McGeechan K, Barratt A, Herbert R (2013) Internet-based randomized controlled trials: a systematic review. J Am Med Inform Assoc 20(3):568-576. https://doi.org/10.1136/amiajnl-2012-001175

19. Smoller WS, Kim MY (2010) Statistical analysis of clinical trials. Semin Nucl Med 40(5):357-363. https://doi.org/10.1053/j.semnuclmed.2010.04.001

20. Schmoor C, Olschewski M, Schumacher M (1996) Randomized and nonrandomized patients in clinical trials: experiences with comprehensive cohort studies. Stat Med 15(3):263-271. https://doi.org/10.1002/(SICI)1097-02 58(19960215) 15:3<263::AID-SIM165>3.0.CO;2-K

21. Altman DG, Schulz KF, Moher D, Egger M, Davidoff F, Elbourne D, Gotzsche PC, Lang T (2001) The revised CONSORT statement for reporting randomized trials: explanation and elaboration. Ann Intern Med 134(8):663694. https://doi.org/10.7326/0003-4819-134-8-200104170-00012

22. Yao F, Singer M, Rosenfeld RM (2007) Randomized controlled trials in otolaryngology journals. Otolaryngol Head Neck Surg 137(4):539-544. https://doi.org/10.1016/j.otohns.2007.07.018

23. Banglawala SM, Lawrence LA, Tobin FE, Soler ZM, Schlosser RJ, Loannidis J (2015) Recent randomized controlled trials in otolaryngology. Otolaryngol Head Neck Surg 152(3):418-423. https://doi.org/10.1177/0194599814563518

\section{Publisher's Note}

Springer Nature remains neutral with regard to jurisdictional claims in published maps and institutional affiliations.

\section{Submit your manuscript to a SpringerOpen ${ }^{\circ}$ journal and benefit from:}

- Convenient online submission

- Rigorous peer review

- Open access: articles freely available online

High visibility within the field

- Retaining the copyright to your article

Submit your next manuscript at $\boldsymbol{\nabla}$ springeropen.com 